\title{
Genome-wide association study of insect bite hypersensitivity in two horse populations in the Netherlands
}

\author{
Anouk Schurink ${ }^{1 *}$, Anna Wolc ${ }^{2,3}$, Bart J Ducro ${ }^{1}$, Klaas Frankena ${ }^{4}$, Dorian J Garrick ${ }^{3}$, Jack CM Dekkers ${ }^{3}$ \\ and Johan AM van Arendonk'
}

\begin{abstract}
Background: Insect bite hypersensitivity is a common allergic disease in horse populations worldwide. Insect bite hypersensitivity is affected by both environmental and genetic factors. However, little is known about genes contributing to the genetic variance associated with insect bite hypersensitivity. Therefore, the aim of our study was to identify and quantify genomic associations with insect bite hypersensitivity in Shetland pony mares and Icelandic horses in the Netherlands.
\end{abstract}

Methods: Data on 200 Shetland pony mares and 146 Icelandic horses were collected according to a matched case-control design. Cases and controls were matched on various factors (e.g. region, sire) to minimize effects of population stratification. Breed-specific genome-wide association studies were performed using $70 \mathrm{k}$ single nucleotide polymorphisms genotypes. Bayesian variable selection method Bayes-C with a threshold model implemented in GenSel software was applied. A 1 Mb non-overlapping window approach that accumulated contributions of adjacent single nucleotide polymorphisms was used to identify associated genomic regions.

Results: The percentage of variance explained by all single nucleotide polymorphisms was $13 \%$ in Shetland pony mares and 28\% in Icelandic horses. The 20 non-overlapping windows explaining the largest percentages of genetic variance were found on nine chromosomes in Shetland pony mares and on 14 chromosomes in Icelandic horses. Overlap in identified associated genomic regions between breeds would suggest interesting candidate regions to follow-up on. Such regions common to both breeds (within $15 \mathrm{Mb}$ ) were found on chromosomes 3, 7, 11, 20 and 23. Positional candidate genes within $2 \mathrm{Mb}$ from the associated windows were identified on chromosome 20 in both breeds. Candidate genes are within the equine lymphocyte antigen class II region, which evokes an immune response by recognizing many foreign molecules.

Conclusions: The genome-wide association study identified several genomic regions associated with insect bite hypersensitivity in Shetland pony mares and Icelandic horses. On chromosome 20, associated genomic regions in both breeds were within $2 \mathrm{Mb}$ from the equine lymphocyte antigen class II region. Increased knowledge on insect bite hypersensitivity associated genes will contribute to our understanding of its biology, enabling more efficient selection, therapy and prevention to decrease insect bite hypersensitivity prevalence.

\footnotetext{
* Correspondence: Anouk3.Schurink@wur.nl

${ }^{1}$ Animal Breeding and Genomics Centre, Wageningen University, P.O. Box 338, Wageningen $6700 \mathrm{AH}$, the Netherlands

Full list of author information is available at the end of the article
} 


\section{Background}

Insect bite hypersensitivity (IBH) is a common allergic skin disease in various horse breeds found throughout the world, and results from bites of Culicoides spp. Sensitive horses develop a severe itch, which results in selfinflicted trauma and severely affected horses sometimes need to be euthanized [1]. Welfare of affected horses is therefore reduced. No cure is available, and methods to prevent or reduce clinical symptoms often require dedication from the owner and greatly differ in efficiency e.g. [1-5]. Owners of affected horses incur costs related to preventive or curative methods and veterinary consultation. Moreover, the commercial value of affected horses is reduced and use of affected horses can be restricted due to discomfort and disfiguration [1].

Insect bite hypersensitivity is a multi-factorial disorder that is affected by environmental and genetic factors. Environmental factors are, among others, related to Culicoides spp. density. Partial genetic control has been confirmed in various horse breeds [6-8]. Monogenic inheritance of sensitivity to IBH has been rejected by segregation analysis [9], which showed a polygenic mode of inheritance. However, little is known on the genes contributing to genetic variance. Genomic research on IBH using a candidate gene approach or genome-wide association study (GWAS) has been limited. Using a candidate gene approach, Andersson et al. [10] showed that variants within the major histocompatibility complex (MHC) class II region are associated with IBH sensitivity. The same allele (COR112:274) increased IBH sensitivity in both Swedish-born Icelandic horses (odds ratio $=4.19$ ) and Exmoor ponies (odds ratio $=1.48$ ). Moreover, homozygosity across the MHC class II region increased IBH sensitivity in both breeds. Serological research on IBH has also shown a significant difference in the distribution of specific MHC antigens between cases and controls [11,12]. The MHC genes in the horse, known as equine lymphocyte antigen (ELA) genes, are located on horse chromosome (Equus caballus) ECA20 and their resulting protein structures recognize many foreign molecules, thereby evoking an immune response [13].

Using GWAS, Schurink et al. [14] found associations between ECA20 and IBH. The identified genomic region was approximately $8 \mathrm{Mb}$ from the $\mathrm{MHC}$ region and was poorly covered in single nucleotide polymorphisms (SNP) from the marker panel. Schurink et al. [14] identified 24 SNP on 12 chromosomes in Shetland pony mares associated with IBH sensitivity $\left(-\log _{10}(\mathrm{p})>2.5\right)$. Insect bite hypersensitivity is observed in many horse breeds throughout the world and could have common genetic components across breeds. Across-breed analyses could facilitate fine-mapping by reducing the length of associated genomic regions, since haplotypes shared across breeds are expected to be shorter than within-breed haplotypes e.g. $[15,16]$.
The aim of our study was to expand these findings through identification and quantification of genomic associations with IBH using phenotypic and SNP information from Shetland pony mares and Icelandic horses in the Netherlands. Knowledge of genomic regions associated with IBH will contribute to our understanding of its biology, enabling more efficient selection, therapy and prevention in order to decrease IBH prevalence.

\section{Methods}

\section{Animals and phenotypes}

Cases were defined as individuals showing clinical IBH symptoms, while controls were free of symptoms despite exposure to Culicoides spp. Selection of cases and controls was described in detail by Schurink et al. [14], and cases and controls were matched on various factors to minimize effects of population stratification. Shetland pony mares were recruited through routine inspections in 2009 and through publications by the studbook in their magazine and on their website in 2010. Shetland pony mares were matched on withers height category, coat colour, location and sire. Icelandic horses were recruited in 2010 through publications on various equine related websites and were matched on coat colour, location, sex, importation from Iceland (yes/no) and sire. Age at onset is generally between 2 and 4 years-of-age e.g. [17]. Therefore, controls were required to be at least 4 years-of-age and to have been at least one year at risk for developing symptoms. Proximity to a case was required to ensure exposure to Culicoides spp. and thereby increase reliability of phenotypes on controls. Paternal half-sibs were sought to minimize population stratification due to pedigree. The dataset (Table 1) contained 200 Shetland pony mares and 146 Icelandic horses. The same Shetland pony mares analysed by Schurink et al. [14] were included in our study, although $70 \mathrm{k}$ genotype data were available, since the mares were re-genotyped.

Participating owners were visited by an experienced veterinarian and researcher to take blood samples, score phenotypes and conduct an IBH related questionnaire (more details in Schurink et al. [14]). All Icelandic horses and most Shetland pony mares $(95.0 \%)$ were scored by the same veterinarian (Table 1) to ensure uniform classification. Blood sample collection from Shetland pony mares and Icelandic horses was approved by the Board on Animal Ethics and Experiments from Wageningen University (experiments 2009055 and 2010109).

\section{Data}

Shetland pony mare data contained 103 cases and 97 controls collected in autumn 2009 or 2010 (Table 1). Data contained half-sib mares $(50.0 \%$ of the data) descending from 41 sires with both case(s) and control(s) 
Table 1 Distribution of characteristics (numbers) of Shetland pony mares and Icelandic horses for cases and controls

\begin{tabular}{|c|c|c|c|c|c|c|}
\hline \multirow[b]{2}{*}{ Trait } & \multicolumn{3}{|c|}{ Shetland pony mares } & \multicolumn{3}{|c|}{ Icelandic horses } \\
\hline & Cases & Controls & Total & Cases & Controls & Total \\
\hline Number of animals & 103 & 97 & 200 & 73 & 73 & 146 \\
\hline \multicolumn{7}{|l|}{ Year of scoring } \\
\hline 2009 & 83 & 78 & 161 & - & - & - \\
\hline 2010 & 20 & 19 & 39 & 73 & 73 & 146 \\
\hline \multicolumn{7}{|l|}{ Month of scoring } \\
\hline September & 52 & 52 & 104 & 22 & 29 & 51 \\
\hline October & 47 & 42 & 89 & 51 & 44 & 95 \\
\hline November & 4 & 3 & 7 & - & - & - \\
\hline \multicolumn{7}{|l|}{ Veterinarian } \\
\hline 1 & 97 & 93 & 190 & 73 & 73 & 146 \\
\hline 2 & 6 & 4 & 10 & - & - & - \\
\hline \multicolumn{7}{|l|}{ Pedigree } \\
\hline Number of sires & 84 & 86 & 129 & 57 & 61 & 95 \\
\hline Number of dams & 100 & 93 & 187 & 68 & 67 & 126 \\
\hline \multicolumn{7}{|l|}{ Age, years } \\
\hline Mean (SD) & $7.1(4.5)$ & $8.3(4.4)$ & $7.7(4.5)$ & $13.1(6.0)$ & $12.6(5.9)$ & $12.8(5.9)$ \\
\hline Range & $0-23$ & $4-22$ & $0-23$ & $4-29$ & $4-35$ & $4-35$ \\
\hline \multicolumn{7}{|l|}{ Sex } \\
\hline Female & 103 & 97 & 200 & 51 & 43 & 94 \\
\hline Male & - & - & - & 22 & 30 & 52 \\
\hline Withers height category & & & & & & $N / A^{a}$ \\
\hline Mini & 28 & 24 & 52 & & & \\
\hline Small & 17 & 18 & 35 & & & \\
\hline Middle & 32 & 27 & 59 & & & \\
\hline Tall & 26 & 28 & 54 & & & \\
\hline Imported from Iceland & & & $N / A^{a}$ & & & \\
\hline Yes & & & & 17 & 2 & 19 \\
\hline No & & & & 56 & 71 & 127 \\
\hline \multicolumn{7}{|l|}{ Coat colour } \\
\hline Bay & 5 & 4 & 8 & 11 & 7 & 18 \\
\hline Black & 51 & 52 & 103 & 16 & 11 & 27 \\
\hline Black paint & 6 & 4 & 10 & 2 & 3 & 5 \\
\hline Chestnut & 26 & 23 & 49 & 8 & 14 & 22 \\
\hline Chestnut paint & 8 & 6 & 14 & - & 2 & 2 \\
\hline Other & 7 & 8 & 15 & 28 & 35 & 63 \\
\hline Silver dapple & - & - & - & 8 & 1 & 9 \\
\hline
\end{tabular}

${ }^{\mathrm{a}} \mathrm{N} / \mathrm{A}=$ not applicable.

among their offspring, and mares (50.0\% of the data) descending from 88 sires with only case(s) or control(s) among their offspring. Mares were located on 73 premises. The number of mares per premise ranged from 1 (23.3\% of all premises) to $9(2.7 \%)$ and the mean number of mares per premise was 2.7 .
Icelandic horse data contained 73 cases and 73 controls collected in autumn 2010 (Table 1). It contained both females (64.4\%) and males (i.e. geldings and stallions; $35.6 \%$ ) (Table 1). In total, $13.0 \%$ of Icelandic horses were imported from Iceland and $87.0 \%$ were born in Europe (mainly the Netherlands) (Table 1). Data contained half-sib 
horses (45.2\% of the data) descending from 23 sires with both case(s) and control(s) among their offspring, and horses $(54.8 \%$ of the data) descending from 72 sires with only case(s) or control(s) among their offspring. Horses were located on 31 premises. The number of horses per premise ranged from 1 (19.4\% of all premises) to 14 (3.2\%) and the mean number of horses per premise was 4.7 .

\section{Genotyping and quality control}

Genotypes from all Shetland pony mares and Icelandic horses were obtained using the equine HD chip (Illumina Inc., San Diego, CA) containing 65157 SNP. Those SNP with a call-rate $<90 \%$ or minor allele frequency $\leq 0.02$ were excluded from the data. Call-rate per animal was considered sufficient (> 90\%) for all animals. The majority (319 out of 346) of animals had a call-rate greater than 99\%. After breed-specific quality control (applying the same quality control to each breed separately), the Shetland pony mare data contained 46888 SNP and the Icelandic horse data contained 51453 SNP.

\section{Population stratification analysis}

Cases and controls were matched on various factors to minimize effects of population stratification and thereby reduce possible spurious associations. To test whether matching of cases and controls in Shetland pony mares and Icelandic horses was successful, the relation between IBH (case or control, binary phenotype) and matching factors was assessed in univariable and multivariable models using the LOGISTIC procedure incorporated in SAS 9.2@ software (SAS Institute Inc., Cary, NC). Fixed effects of withers height category, coat colour, sex, import from Iceland, veterinarian and month and year of scoring, and the covariate of age of the animal were tested for significance.

Similar genomic kinship within and across cases and controls indicates successful matching on pedigree. Breed-specific genomic kinship among animals was therefore computed using the $i b s$ function of the R package GenABEL [18] as:

$$
f_{i, j}=\Sigma_{k} \frac{\left(x_{i, k}-p_{k}\right)\left(x_{j, k}-p_{k}\right)}{\left(p_{k}\left(1-p_{k}\right)\right)},
$$

where $f_{i, j}$ is the genomic kinship (identity-by-state) between animal $i$ and $j$, based on $k=48810$ autosomal SNP in Icelandic horses (SNP with call-rate $<90 \%$, monomorphic SNP and SNP on the X chromosome excluded) and 44576 autosomal SNP in Shetland pony mares; $x_{i, k}$ or $x_{j, k}$ are the genotypes (coded as $0,1 / 2,1$ ) of the $\mathrm{i}^{\text {th }}$ or $\mathrm{j}^{\text {th }}$ animal for SNP $k$ and $p_{k}$ is the frequency of the allele (top strand). The genomic kinship matrix was transformed to a distance matrix to perform classical multidimensional scaling [19], which returned the first two principal components. The principal components for each breed were plotted to visualize distances between animals and more specifically between cases and controls. Further, Icelandic horses were categorized into 'imported from Iceland' or 'born in Europe' to see whether their genetic background differed.

\section{Genome-wide association study}

Breed-specific GWAS were performed using genotypes from the same marker panel but the number of SNP after quality control differed between Shetland pony mares $(\mathrm{n}=46888)$ and Icelandic horses $(\mathrm{n}=51$ 453). The Bayesian variable selection method Bayes- $C$ with a threshold model, described by Kizilkaya et al. [20] and implemented in the GenSel software (http://bigs.ansci.iastate.edu/), was used to identify and quantify genomic regions associated with IBH. Method Bayes- $C$ assumes a common variance for all SNP in the model and is less sensitive to the prior for genetic variance e.g. [21-23] compared to Bayes-B as described by Meuwissen et al. [24]. Method Bayes- $C$ fits all SNP simultaneously using a mixture threshold model and assuming additive SNP effects:

$$
\eta=\mu+\sum_{j=1}^{K} Z_{j} u_{j} \delta_{j}
$$

where $\eta$ is the linear predictor that is related to observed IBH phenotypes (case/control) through a probit link function and was sampled during each iteration from a normal distribution that comprises the liability scale corresponding to the observed threshold score following Sorensen et al. [25]; $\mu$ is an overall mean; $K$ is the number of SNP; $Z_{j}$ is the column vector representing the genotype covariate at $\mathrm{SNP} j$ (input as $\mathrm{AA}=-10, \mathrm{AB}=0, \mathrm{BB}=10$ with missing genotypes set to the average value of the particular SNP in the data set); $u_{j}$ is the random allele substitution effect of SNP $j$, and $\delta_{j}$ is a random $0 / 1$ variable indicating the absence (with probability $\pi$ ) or presence (with probability $1-\pi$ ) of SNP $j$ in the model.

In our analyses, $\pi$ was set to 0.999 , resulting in roughly 30 to 70 SNP being included in the model in any particular iteration. Fewer SNP than individuals were fitted in any iteration to decrease the risk of overfitting the data, and previous work [14] showed that a limited number of SNP reach significance level. The allele substitution effect for SNP $j\left(u_{j}\right)$ was assumed normally distributed $\sim N\left(0, \sigma_{u}^{2}\right)$ conditional on $\sigma_{u}^{2}$ when $\operatorname{SNP} j$ was included in the model $\left(\delta_{j}=1\right)$, but $u_{j}$ was 0 when $\delta_{j}=0$. Variance $\sigma_{u}^{2}$ was assumed to follow a scaled inverse chisquare distribution with $v_{u}=4$ degrees of freedom and scale parameter $S_{u}^{2}$, which was derived from the additive genetic variance as $\frac{\sigma_{a}^{2}}{K(1-\pi) 2 \bar{p} \bar{q}}$ according to Gianola et al. [26] and Kizilkaya et al. [20]. The prior of $\sigma_{u}^{2}$ was derived from the heritability of IBH on the liability scale (= 24\%), 
as estimated in a pedigree-based population genetic analysis by Schurink et al. [7]. Residual variance $\sigma_{e}^{2}$ is not identifiable and was set to 1 and not sampled. Sampling of effects is described in more detail by Kizilkaya et al. [20]. A total of 200000 Markov chain Monte Carlo (MCMC) iterations were run, with a burn-in period of 20000 iterations.

Model frequency, i.e. the proportion of total post burn-in iterations in which a particular SNP was included in the model, was used as evidence for an associated SNP. However, if consecutive SNP are in high linkage disequilibrium (LD) with a particular quantitative trait locus (QTL), effects and model frequencies may be distributed across those SNP, and effects and model frequencies of individual SNP will completely capture the effects of the QTL. Thus, a window approach, which accumulates effects of adjacent SNP, was used to better identify genomic regions associated with QTL [27].

The approach described by Wolc et al. [28] and implemented in version 4.0 of the GenSel software (http:// bigs.ansci.iastate.edu/) was used to identify associated windows (i.e. genomic regions). For this purpose, physical map order (build EquCab2.0) was used to allocate SNP to consecutive non-overlapping $1 \mathrm{Mb}$ windows $(\mathrm{n}=$ 2376), and the posterior distribution of the percentage of genomic variance explained by each of these windows was derived. For this purpose, the variance of genomic breeding values for each window (= window genomic variance) was computed among individuals for every $100^{\text {th }}$ iteration of the MCMC chain based on the marker effects sampled in that iteration. Window genomic variance was divided by genomic variance explained (sum of all SNP) across the genome in that particular iteration to determine the percentage of genomic variance explained by the window. The resulting posterior distribution of the \% variance of each window was used for testing. The posterior distribution included results from iterations that excluded the window (or SNP) from the model. Window genomic variance greater than $0.04 \%$ [i.e. the expected percentage of variance explained by each window in an infinitesimal model $\left.\left(\frac{1}{2376} \times 100\right)\right]$, was used as a threshold to declare regions that explained more variance than expected.

\section{Results}

\section{Phenotypes and questionnaire results}

Questionnaire results from Shetland pony mare and Icelandic horse cases are shown in Table 2. In Icelandic horses, questionnaire data from 14 out of 73 cases was missing. The observed clinical symptoms of $\mathrm{IBH}$ in all cases are summarized in Table 3. Severity of itch was lower in Icelandic horse cases compared with Shetland
Table 2 Questionnaire results (numbers) from Shetland pony mare and Icelandic horse cases of insect bite hypersensitivity

\begin{tabular}{lll}
\hline Trait & $\begin{array}{l}\text { Shetland } \\
\text { pony mares }\end{array}$ & $\begin{array}{l}\text { Iceland } \\
\text { horses }\end{array}$ \\
\hline
\end{tabular}

Age at onset

Younger than 2 years 10

2 to 5 years

$64 \quad 30$

6 to 10 years

11 years or older

Unknown

Duration IBH

1 year

2 years

3 years or more

Unknown

Onset of symptoms

Spring

Summer

Autumn

Unknown

64

30

16

2

11

6

9

Disappearance of symptoms

Summer

Autumn

Winter

Chronic

Unknown

Severity of symptoms over years

Increases

18

23

57

Decreases

Remains equal

Varies

Unknown

48

6

26

-

5

6

Severity of itch

Mild

Moderate

Severe

Unknown

Preventive or curative measures

Yes

No

Applied measures ${ }^{\mathrm{a}}$

Eczema blankets

Local treatment with oil or cream

Insecticide

Related to nutrition

Stabling

$9 \quad 1$

7

an several cases more than one preventive measure was applied; sum of applied measures per breed therefore exceeded the total number of cases per breed. 
Table 3 Insect bite hypersensitivity symptoms on various locations in Shetland pony mare and Icelandic horse cases

\begin{tabular}{lcc}
\hline & $\begin{array}{c}\text { Shetland pony } \\
\text { mare cases }\end{array}$ & $\begin{array}{c}\text { Icelandic } \\
\text { horse cases }\end{array}$ \\
\hline Clinical symptoms & 100 & 71 \\
Hair loss & 89 & 71 \\
Thickening of skin & 26 & 17 \\
Crusting & 9 & 4 \\
Scaling & 9 & 1 \\
Open wounds & & \\
Affected location & 102 & 72 \\
Crest & 86 & 61 \\
Base of the tail & 22 & - \\
Hindquarters & 4 & 12 \\
Head & 1 & 8 \\
Abdomen & 4 & - \\
Other & & \\
\hline
\end{tabular}

Clinical symptoms were scored by an experienced veterinarian and are presented as the number of cases with this particular clinical symptom; in total, 103 Shetland pony mare cases and 73 Icelandic horse cases were scored.

pony mare cases (Table 2), probably because eczema blankets (a preventive measure) were used in many Icelandic horse cases. Preventive or curative measures were applied more often for Icelandic horse cases than for Shetland pony mare cases (Table 2) and more measures per case were applied to Icelandic horse cases compared to Shetland pony mare cases. Owners of cases replied that they experienced negative effects of IBH, as it reduces equine welfare, requires much time and limits rideability and marketability. For both Icelandic horses and Shetland pony mares, questionnaire results and observed clinical symptoms agreed with the typical course of IBH e.g. [29].

\section{Population stratification analysis}

Matching of Shetland pony mares to minimize effects of population stratification was successful, as none of the matching factors had a significant effect on IBH $(\mathrm{p}<$ $0.05)$. Analysis of matching factors in Icelandic horses indicated that import from Iceland $(p=0.002)$ had a significant effect on IBH.

To test whether matching of cases and controls based on sire was successful, breed-specific genomic kinship among animals was computed based on identity-by-state of SNP genotypes. Figures 1 and 2 show the first two principal components of the transformed breed-specific kinship matrices to visualize genetic distances between animals. The multidimensional scaling plots showed a high degree of overlap between cases and controls in both Shetland pony mares and Icelandic horses (Figure 1). Effects of population stratification due to pedigree were therefore limited.

Two imported approved stallion cases were more distant to the other Icelandic horses in our dataset, although the imported Icelandic horses seemed to originate from a similar genetic background (Figure 2). However, imported Icelandic horses $(\mathrm{n}=17$ cases and $\mathrm{n}=$ 2 controls) were removed from the analyses due to less successful matching of Icelandic horses on import status (Table 1 and $p=0.002$ for import status). The final Icelandic horse data therefore included 56 cases and 71 controls and were all born in Europe.
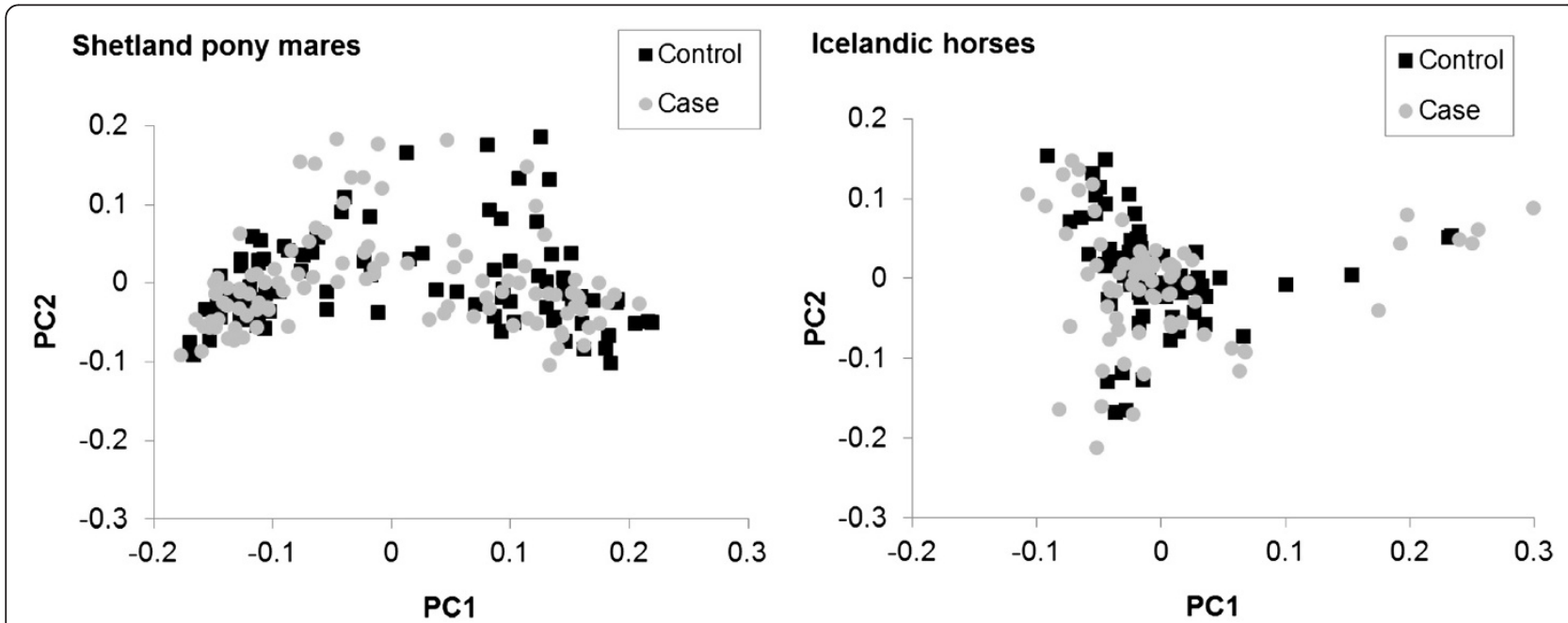

Figure 1 Multi-dimensional scaling plots of the genetic distance between animals in Shetland pony mares and Icelandic horses. Each point corresponds to one animal and indicates the distance between animals represented by the first two principal components (PC1 and PC2), based on the genomic kinship matrices. 


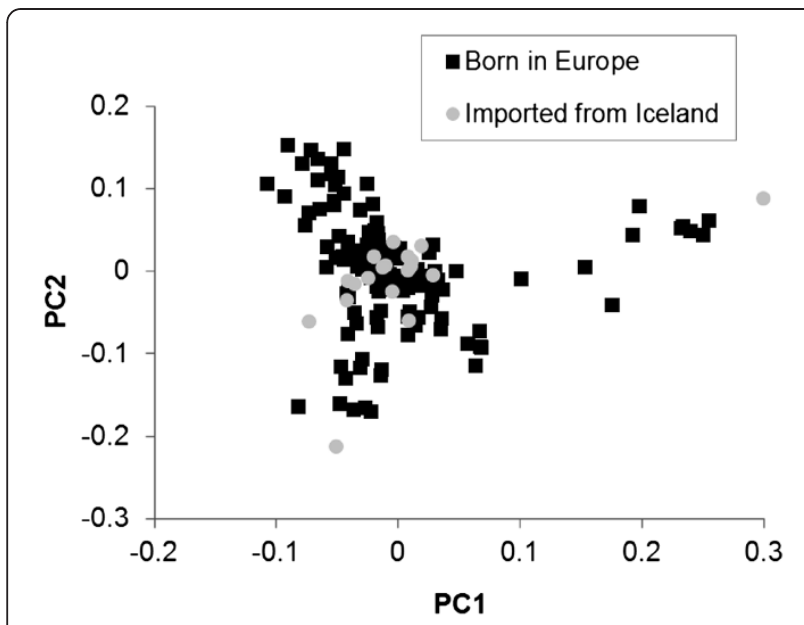

Figure 2 Multi-dimensional scaling plot of the genetic distance between imported Icelandic horses and Icelandic horses born in Europe. Each point corresponds to one animal and indicates the distance between animals represented by the first two principal components (PC1 and PC2), based on the genomic kinship matrices.

\section{Genome-wide association study}

In Shetland pony mares, $13 \%$ of variance was explained by all SNP, which is lower than the pedigree-based estimate of heritability of IBH on the liability scale $(24 \%$, $\mathrm{SE}=6 \%$ ) in Shetland pony mares in the Netherlands [7]. The 20 non-overlapping windows that explained the largest percentages of genetic variance were located on nine chromosomes (Table 4). The percentage of genetic variance explained by the top 20 associated windows ranged from 0.62 to $0.14 \%$ (Table 4 ) and was highest for the window on chromosome 20 position $35 \mathrm{Mb}$ (Table 4). In 2.7 to $5.3 \%$ of iterations of the MCMC (Table 4), the percentage of variance explained by a window exceeded the expected percentage of variance explained (i.e. $0.04 \%$ ). For each of the top 20 associated windows, the SNP with the highest model frequency is presented in Table 4, including the frequency of the unfavourable allele in cases and controls.

In Icelandic horses born in Europe, 28\% of variance was explained by all SNP, which is equal to the pedigree-

Table 4 Windows explaining the largest percentages of insect bite hypersensitivity genetic variance in Shetland pony mares

\begin{tabular}{|c|c|c|c|c|c|c|c|c|c|}
\hline \multicolumn{5}{|c|}{ Top 20 associated windows ${ }^{a}$} & \multicolumn{5}{|c|}{ SNP with highest model frequency within window } \\
\hline \multirow[t]{2}{*}{$\mathrm{ECA}^{\mathrm{b}}$} & \multirow[t]{2}{*}{$\begin{array}{l}\text { Position } \\
(\mathrm{Mb})^{\mathrm{c}}\end{array}$} & \multirow{2}{*}{$\begin{array}{l}\text { \% of genetic } \\
\text { variance } \\
\text { explained }^{d}\end{array}$} & \multirow[t]{2}{*}{$\begin{array}{l}\text { Number } \\
\text { of SNP }\end{array}$} & \multirow{2}{*}{$\begin{array}{l}\% \text { of iterations } \\
\text { where variance } \\
\text { explained }>0.04 \%\end{array}$} & \multirow[t]{2}{*}{ SNP name } & \multirow[t]{2}{*}{$\begin{array}{l}\text { SNP position } \\
\text { (bp) }\end{array}$} & \multirow[t]{2}{*}{$\begin{array}{l}\text { Model } \\
\text { frequency }\end{array}$} & \multicolumn{2}{|c|}{$\begin{array}{c}\text { Allele } \\
\text { frequency }\end{array}$} \\
\hline & & & & & & & & Cases & Controls \\
\hline 3 & 8 & 0.143 & 21 & 2.8 & BIEC2_810809 & $8,098,240$ & 0.29 & 0.67 & 0.54 \\
\hline 3 & 17 & 0.141 & 30 & 3.1 & BIEC2_773375 & $17,036,655$ & 0.38 & 0.62 & 0.46 \\
\hline 3 & 50 & 0.270 & 27 & 3.8 & BIEC2_779930 & $50,444,836$ & 0.68 & 0.45 & 0.29 \\
\hline 3 & 51 & 0.161 & 25 & 3.2 & BIEC2_780595 & $51,525,184$ & 0.35 & 0.58 & 0.43 \\
\hline 7 & 67 & 0.149 & 27 & 3.3 & BIEC2_1005528 & $67,597,722$ & 0.36 & 0.67 & 0.54 \\
\hline 7 & 85 & 0.171 & 24 & 2.9 & BIEC2_1010550 & $85,800,251$ & 0.29 & 0.64 & 0.52 \\
\hline 8 & 63 & 0.231 & 22 & 3.8 & BIEC2_1058160 & $63,839,900$ & 0.47 & 0.59 & 0.44 \\
\hline 11 & 22 & 0.201 & 21 & 3.6 & BIEC2_143974 & $22,769,190$ & 0.32 & 0.50 & 0.35 \\
\hline 11 & 23 & 0.149 & 24 & 3.1 & BIEC2_144465 & $23,873,176$ & 0.31 & 0.59 & 0.45 \\
\hline 11 & 26 & 0.178 & 26 & 3.3 & BIEC2_145801 & $26,946,633$ & 0.20 & 0.51 & 0.39 \\
\hline 11 & 32 & 0.193 & 31 & 4.1 & BIEC2_149137 & $32,010,755$ & 0.37 & 0.27 & 0.13 \\
\hline 17 & 1 & 0.141 & 24 & 2.7 & BIEC2_366411 & $1,024,001$ & 0.27 & 0.45 & 0.31 \\
\hline 17 & 6 & 0.147 & 28 & 2.6 & BIEC2_367597 & $6,640,619$ & 0.29 & 0.65 & 0.51 \\
\hline 17 & 75 & 0.303 & 23 & 4.4 & BIEC2_384363 & $75,401,514$ & 0.67 & 0.67 & 0.52 \\
\hline 17 & 76 & 0.159 & 18 & 2.3 & BIEC2_385267 & $76,776,877$ & 0.81 & 0.70 & 0.55 \\
\hline 20 & 35 & 0.624 & 23 & 5.3 & UKUL3474 & $35,643,200$ & 2.03 & 0.56 & 0.37 \\
\hline 20 & 41 & 0.176 & 21 & 2.9 & BIEC2_532511 & $41,520,518$ & 0.84 & 0.45 & 0.28 \\
\hline 23 & 14 & 0.143 & 25 & 2.8 & TBIEC2_645769 & $14,286,784$ & 0.16 & 0.36 & 0.27 \\
\hline 27 & 13 & 0.214 & 18 & 3.2 & BIEC2_705454 & $13,198,799$ & 0.78 & 0.71 & 0.54 \\
\hline 28 & 41 & 0.154 & 24 & 3.2 & BIEC2_744415 & $41,130,845$ & 0.24 & 0.73 & 0.61 \\
\hline
\end{tabular}

${ }^{\mathrm{a}}$ top $201 \mathrm{Mb}$ non-overlapping windows explaining the largest percentages of genetic variance; ${ }^{\mathrm{b}}$ Equus caballus autosome; ${ }^{\mathrm{c}}$ position of the window in Mb pairs, where for instance window position $8 \mathrm{Mb}$ includes SNP located on that particular chromosome between 8 to $9 \mathrm{Mb}$; ${ }^{\mathrm{d}}$ percentage of total genetic variance explained by $1 \mathrm{Mb}$ non-overlapping windows of consecutive SNP based on physical order (build EquCab2.0), averaged across post burn-in iterations, thereby including results from iterations that excluded the window from the model; ${ }^{e}$ percentage of iterations (out of 1799 saved) during which the window captured over $0.04 \%$ of genomic variance (i.e. the expected percentage of variance explained by each window in an infinitesimal model); ${ }^{f}$ percentage of iterations where SNP was modelled to have an effect; ${ }^{9}$ frequency of the unfavourable allele. 
based estimate of heritability of IBH on the liability scale $(27 \%, \mathrm{SE}=17 \%)$ in Swedish-born Icelandic horses [6]. The 20 windows explaining the largest percentages of genetic variance were located on 14 chromosomes (Table 5). The percentage of genetic variance explained by the top 20 associated windows ranged from 0.66 to $0.14 \%$ (Table 5) and was highest for the window on chromosome $\mathrm{X}$ position $59 \mathrm{Mb}$ (Table 5). In 2.2 to $7.9 \%$ of iterations of the MCMC (Table 5), the percentage of variance explained by a window exceeded the expected percentage of variance explained (i.e. 0.04\%). For each of the top 20 associated windows, the SNP with the highest model frequency is presented in Table 5.

A comparison of associated genomic regions in Shetland pony mares and Icelandic horses (using the percentage of genetic variance explained by $1 \mathrm{Mb}$ non-overlapping windows in the breed-specific GWAS) is depicted in Figure 3. An overlap in the top 20 associated genomic regions $(\geq 0.14 \%$ of genomic variance explained) was found on chromosomes 3, 7, 11, 20 and 23 (within 5 to $15 \mathrm{Mb}$ ), and represent the most promising candidate regions to follow-up on.

\section{Discussion}

The aim of this study was to identify and quantify genomic regions associated with IBH in Shetland pony mares and Icelandic horses in the Netherlands. Breedspecific GWAS were performed and overlapping associated genomic regions (within $15 \mathrm{Mb}$ or less) were identified in both breeds.

\section{Population stratification analysis}

Data were gathered according to a matched case-control design to limit unwanted spurious associations due to population stratification, which might be caused by confounding of 'the trait of interest' with pedigree and other relevant (e.g. environmental) effects e.g. [30]. Population stratification due to pedigree was minimized by including

Table 5 Windows explaining the largest percentages of genetic variance for insect bite hypersensitivity in Icelandic horses

\begin{tabular}{|c|c|c|c|c|c|c|c|c|c|}
\hline \multicolumn{5}{|c|}{ Top-20 associated windows ${ }^{\mathrm{a}}$} & \multicolumn{5}{|c|}{ SNP with highest model frequency within window } \\
\hline \multirow[t]{2}{*}{$\mathrm{ECA}^{\mathrm{b}}$} & \multirow[t]{2}{*}{$\begin{array}{l}\text { Position } \\
(\mathrm{Mb})^{\mathrm{c}}\end{array}$} & \multirow{2}{*}{$\begin{array}{l}\% \text { of genetic } \\
\text { variance }^{\text {explained }}{ }^{d}\end{array}$} & \multirow[t]{2}{*}{$\begin{array}{l}\text { Number } \\
\text { of SNP }\end{array}$} & \multirow{2}{*}{$\begin{array}{l}\% \text { of iterations } \\
\text { where variance } \\
\text { explained }>0.04 \%{ }^{\mathrm{e}}\end{array}$} & \multirow[t]{2}{*}{ SNP name } & \multirow[t]{2}{*}{$\begin{array}{l}\text { SNP position } \\
\text { (bp) }\end{array}$} & \multirow[t]{2}{*}{$\begin{array}{l}\text { Model } \\
\text { frequency }\end{array}$} & \multicolumn{2}{|c|}{$\begin{array}{c}\text { Allele } \\
\text { frequency }\end{array}$} \\
\hline & & & & & & & & Cases & Controls \\
\hline 1 & 7 & 0.215 & 25 & 4.5 & BIEC2_2768 & $7,759,159$ & 0.94 & 0.69 & 0.46 \\
\hline 3 & 35 & 0.392 & 18 & 5.4 & BIEC2_776785 & $35,897,049$ & 0.45 & 0.46 & 0.26 \\
\hline 4 & 24 & 0.161 & 17 & 2.7 & BIEC2_855840 & $24,611,718$ & 0.32 & 0.51 & 0.33 \\
\hline 4 & 43 & 0.180 & 18 & 4.0 & BIEC2_861849 & $43,590,939$ & 0.51 & 0.69 & 0.49 \\
\hline 5 & 26 & 0.176 & 20 & 3.2 & BIEC2_898729 & $26,364,893$ & 0.52 & 0.60 & 0.38 \\
\hline 6 & 6 & 0.166 & 43 & 4.4 & BIEC2_937490 & $6,127,639$ & 0.69 & 0.54 & 0.30 \\
\hline 7 & 55 & 0.179 & 24 & 3.8 & BIEC2_1001715 & $55,888,542$ & 0.36 & 0.35 & 0.18 \\
\hline 9 & 78 & 0.182 & 30 & 3.9 & BIEC2_1106244 & $78,254,394$ & 0.44 & 0.43 & 0.25 \\
\hline 11 & 40 & 0.266 & 21 & 3.5 & BIEC2_152809 & $40,721,405$ & 1.30 & 0.67 & 0.42 \\
\hline 15 & 19 & 0.162 & 23 & 3.7 & BIEC2_293503 & $19,944,954$ & 0.66 & 0.55 & 0.34 \\
\hline 15 & 20 & 0.211 & 22 & 3.1 & BIEC2_293623 & $20,074,216$ & 1.04 & 0.68 & 0.44 \\
\hline 15 & 32 & 0.142 & 23 & 3.2 & BIEC2_301468 & $32,220,117$ & 0.31 & 0.59 & 0.41 \\
\hline 15 & 33 & 0.381 & 32 & 4.9 & BIEC2-301721 & $33,565,370$ & 2.23 & 0.70 & 0.42 \\
\hline 18 & 32 & 0.179 & 27 & 3.9 & BIEC2_431445 & $32,561,292$ & 0.69 & 0.54 & 0.34 \\
\hline 19 & 15 & 0.186 & 24 & 3.5 & BIEC2_430270 & $15,644,656$ & 0.45 & 0.54 & 0.35 \\
\hline 19 & 21 & 0.151 & 26 & 3.3 & BIEC2_431289 & $21,754,514$ & 0.33 & 0.75 & 0.57 \\
\hline 20 & 30 & 0.162 & 17 & 2.2 & BIEC2_528135 & $30,619,697$ & 0.87 & 0.78 & 0.53 \\
\hline 23 & 4 & 0.159 & 27 & 3.4 & BIEC2_637804 & $4,466,955$ & 0.49 & 0.74 & 0.55 \\
\hline$x$ & 59 & 0.658 & 29 & 7.9 & BIEC2_1126534 & $59,703,839$ & 1.04 & 0.58 & 0.33 \\
\hline$x$ & 60 & 0.282 & 29 & 3.6 & BIEC2_1126713 & $60,238,370$ & 1.32 & 0.59 & 0.33 \\
\hline
\end{tabular}

${ }^{\mathrm{a}}$ top $201 \mathrm{Mb}$ non-overlapping windows explaining the largest percentages of genetic variance; ${ }^{\mathrm{b}}$ Equus caballus autosome; ${ }^{\mathrm{c}}$ position of the window in Mb pairs, where for instance window position $7 \mathrm{Mb}$ includes SNP located on that particular chromosome between 7 to $8 \mathrm{Mb}$; ${ }^{\mathrm{d}}$ percentage of total genetic variance explained by $1 \mathrm{Mb}$ non-overlapping windows of consecutive SNP based on physical order (build EquCab2.0), averaged across post burn-in iterations, thereby

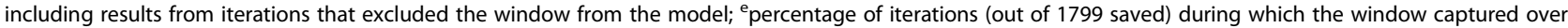
$0.04 \%$ of genomic variance (i.e. the expected percentage of variance explained by each window in an infinitesimal model); ${ }^{f}$ percentage of iterations where SNP was modelled to have an effect; ${ }^{9}$ frequency of the unfavourable allele. 

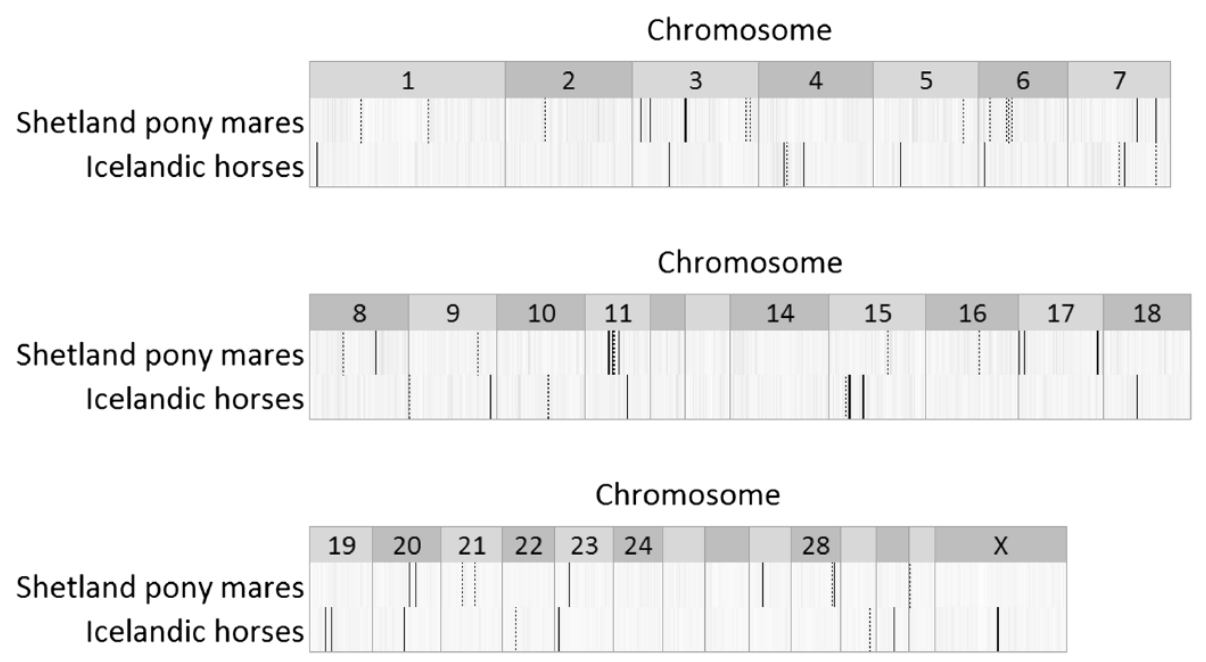

Figure 3 Heat map comparing the percentage of genetic variance of insect bite hypersensitivity explained by each window in Shetland pony mares and Icelandic horses born in Europe. Non-overlapping $1 \mathrm{Mb}$ windows are based on the physical order of consecutive SNP across the genome (ECA1 to X; build EquCab2.0); black bars represent windows explaining $\geq 0.14 \%$ of genetic variance and dashed black bars represent windows explaining between 0.12 and $0.14 \%$ of genetic variance; diminishing grey colour represents a decrease in genetic variance $(<0.12 \%)$ explained by windows.

paternal half-sib pairs. The multidimensional scaling plots based on breed-specific genomic kinship showed a high degree of overlap between cases and controls (Figure 1). Also, the Bayes method accounts for population stratification due to pedigree by fitting all SNP simultaneously e.g. [31]. In Shetland pony mares, confounding of IBH with relevant effects such as region and withers height category was negligible, since the analysis revealed no significant association between IBH and these effects. In Icelandic horses, importation from Iceland had a significant effect on IBH $(p=0.002)$. Our results showed (Figure 2$)$ that differences in genetic background between imported Icelandic horses and Icelandic horses born in Europe were limited, which agrees with Broström et al. [32] and Andersson et al. [10]. However, Culicoides spp. is absent in Iceland and consequently IBH is not observed e.g. [33]. Increased environmental pressure after export and lack of exposure to Culicoides spp. before export are suggested to result in increased incidence and more severe cases after export e.g. [32,34]. The insect bite hypersensitivity statuses of imported Icelandic horses and Icelandic horses born in Europe may not represent the exact same phenotype. The final Icelandic horse data, therefore, only included horses born in Europe.

\section{Single SNP and multi-locus models}

Schurink et al. [14] published genomic regions associated with IBH in 188 Shetland pony mares using $50 \mathrm{k}$ SNP genotypes. In our study, several similar associated genomic regions within $1 \mathrm{Mb}$ distance were identified in Shetland pony mares on chromosomes 3, 11, 20 and 27.
However, Schurink et al. [14] used logistic regression fitting single SNP effects, while our Bayes-C method fitted all SNP simultaneously. Mucha et al. [35] concluded that estimated variances of identified QTL were not overestimated when all SNP were fitted simultaneously, since the variance explained will be distributed across all SNP in high LD with the QTL and therefore cannot exceed the total variance (in contrast to single SNP analysis). Indeed, Sahana et al. [36] compared various association mapping methods and showed that a Bayesian variable selection model that fitted all SNP simultaneously performed best overall. The Bayesian variable selection model using the posterior probability of a QTL in $1 \mathrm{cM}$ overlapping regions to identify associated genomic regions had the highest power to map small QTL (i.e. explaining $2 \%$ of genetic variance) and most precise estimates of QTL location. However, a mixed model analysis fitting random additive genetic effects and testing single SNP performed almost as well, although it was computationally more demanding and multiple testing correction was needed. Like in Sahana et al. [36], analysis of the Shetland pony mare data using logistic regression with single SNP effects, as in Schurink et al. [14], was computationally much more demanding than the Bayesian variable selection method used here and ignored dependencies between SNP. Although several similar associated genomic regions were identified using these two methods, Bayesian variable selection model using posterior probabilities of genomic regions is preferred as it is computationally less demanding, it does not require correction for multiple testing and it accounts for 
population stratification due to pedigree by fitting all SNP simultaneously.

\section{Non-overlapping window approach}

The window approach takes LD between SNP into account and is therefore a better criterion for QTL identification than posterior probabilities of single SNP $[23,36]$. However, optimal choice of the size of a window is not clear, as a specific window may contain more than one QTL or a QTL may be spread over more than one window [27]. For example, after merging windows at 75 and $76 \mathrm{Mb}$ on chromosome 17 in Shetland pony mares and performing another GWAS, the percentage of variance explained by this $2 \mathrm{Mb}$ genomic region was 0.426 , which roughly equals the sum of genetic variance explained by the two separate $1 \mathrm{Mb}$ windows (Table 4). Because these $1 \mathrm{Mb}$ windows were consecutive, the percentage of variance explained by the $2 \mathrm{Mb}$ windows might be considered as total QTL variance (if indeed the two consecutive $1 \mathrm{Mb}$ windows represent the same QTL), whereas the percentage of variance explained by each $1 \mathrm{Mb}$ might each represent a proportion of QTL variance. However, the true QTL position might not be contained in the window with strongest association. Precision of QTL mapping depends on several factors, such as the method of analysis, marker density, sample size and variance explained by the QTL [37]. In a simulated data set of binary phenotypes and SNP genotypes by Mucha et al. [35], the mean distance of estimates from true QTL positions ranged from 0.30 to $0.77 \mathrm{Mb}$, depending on the method of analysis used. However, the SNP density simulated by Mucha et al. [35] was higher than in our study. Because LD can differ between genomic regions e.g. [38,39], LD within a genomic region could be used to determine the optimal size of a window in a given region, although further research is needed to determine the relationship between LD structure and optimal window size.

\section{Genome-wide association study}

Associated genomic regions identified in both breeds (Figure 3) suggest interesting candidate genomic regions to follow-up on. A simultaneous GWAS of both breeds is expected to increase power to detect associations, as more data would be included. However, GWAS across breeds will be less likely to detect SNP that are in LD with QTL in only one breed and will be more likely to detect SNP in LD with QTL across both breeds, provided LD phase is conserved across breeds e.g. [40,41]. To meet these requirements, SNP and QTL need to be physically close or, ideally, represent the actual mutation (which is unlikely). De Roos et al. [41] concluded that roughly $50000 \mathrm{SNP}$ are required to have sufficient LD (i.e. $\geq 0.20$ ) for genomic selection within a dairy cattle breed but that 300000 SNP are required to find SNP that are in LD with the QTL across breeds. Persistency of LD phase extended less than $10 \mathrm{~kb}$ between bovine breeds that diverged hundreds of generations ago [41]. The consistency of LD phase between Shetland ponies and Icelandic horses was not investigated. Shetland ponies and Icelandic horses did cluster together in the phylogenetic analysis of van de Goor et al. [42], which used equine short tandem repeat loci. However, divergence of the breeds occurred many generations ago, thus LD from the ancestral population is expected to have been broken down [43]. Also, the current equine SNP density results in insufficient LD (roughly 0.3 [44]) to expect to find SNP that are in LD with QTL across breeds.

\section{Candidate genes}

Research on IBH using the candidate gene approach or GWAS in horses has been limited. Using a candidate gene approach, Andersson et al. [45] concluded that SPINK5 (serine peptidase inhibitor, Kazal type 5) on ECA14 was not associated with IBH in Swedish-born Icelandic horses. In our study, no genomic regions associated with IBH were found on ECA14. Hořin et al. [46] investigated polymorphisms in various immune response related genes to identify associations with $R$. equi and $L$. intracellularis that cause respectively lung and gastrointestinal infections in horses. Several polymorphisms were significantly associated with these infections, including microsatellite locus HMS01 on ECA15. Marti et al. [47] in [48] concluded that locus HMSO1 is associated with IBH. In our study, genomic regions associated with IBH were identified on ECA15 but only in Icelandic horses. Various IL1 (interleukin 1) related genes are located in or around these regions.

We anticipated a common genetic background of IBH across breeds, although breed-specific genetic influences on IBH cannot be excluded. However, SNP densities within genomic regions could differ between Shetland pony mares and Icelandic horses due to breed-specific edits based on MAF and call-rate. Also, LD between SNP and QTL might be present in one breed but absent in the other e.g. [41], thereby impeding validation of QTL across breeds. Associated genomic regions identified in both Shetland pony mares and Icelandic horses were considered most interesting to follow-up on and were found on ECA3, 7, 11, 20 and 23 (Figure 3, Tables 4 and 5). However, positional candidate genes adjacent to associated genomic regions were identified only for the genomic region on ECA20. No other candidate gene with known function in immunology or allergy was identified in or adjacent to across-breed associated genomic regions. The equine lymphocyte antigen (ELA) class II region is located on ECA20 (spanning 32 and 
$33 \mathrm{Mb}$ ) between the associated genomic regions identified in the Shetland pony mares and Icelandic horses (Tables 4 and 5, Figure 3). ELA, or equine major histocompatibility complex, evokes an immune response by recognizing many foreign molecules [13]. Both serological $[11,12]$ and genomic research [10] have identified an association between ELA class II antigens and IBH. Andersson et al. [10] concluded that the same allele at an ELA locus is associated with IBH in two distinct horse breeds and homozygosity across the ELA region increased IBH sensitivity. An association with IBH on ECA20 was also found by Schurink et al. [14], although the identified region was approximately $8 \mathrm{Mb}$ away from the ELA class II region. However, coverage within the region was poor for the Illumina ${ }^{\circledR}$ EquineSNP50 Genotyping BeadChip (Illumina Inc.) used by Schurink et al. [14], but improved in the current equine HD chip. Associated genomic regions on ECA20 that were identified in the Shetland pony mares and Icelandic horses were within $2 \mathrm{Mb}$ from the ELA class II region, which is reasonably close to confirm the impact of ELA class II region on IBH.

\section{Conclusions and implications}

The genome-wide association study performed here identified several genomic regions associated with IBH in both Shetland pony mares and Icelandic horses. On ECA20, associated genomic regions were identified in both breeds that were within $2 \mathrm{Mb}$ from the equine lymphocyte antigen class II region containing candidate genes. Knowledge on genes associated with IBH will contribute to our understanding of its biology, enabling more efficient therapy, prevention and selection in order to decrease IBH prevalence. Sequencing candidate genes within the equine lymphocyte antigen class II region might identify the functional mutation. Selection on functional mutations, i.e. direct markers, is more effective than indirect markers (i.e. LD and linkage equilibrium markers) [49]. However, genetic gain for marker-assisted selection using only a small number of significant markers to trace a limited number of QTL (although often with larger effects) is likely to be small because a large number of QTL are expected to explain genetic variation in complex traits e.g. [16]. In genomic selection, dense genome-wide markers are used to estimate genomic breeding values based on marker effects across the entire genome. Marker density is assumed to be sufficient so that each QTL is in LD with at least one marker or with a set of markers. Therefore, genomic selection could potentially capture the total genetic variance for a complex trait e.g. [16]. Possibilities for genomic selection on IBH in horse populations or even across horse populations and corresponding implications must be investigated before implementation is considered.
Competing interests

The authors declare that they have no competing interests.

\section{Authors' contributions}

AS acquired the data, carried out the genome-wide association study and drafted the manuscript. BJD, KF and JAMA made substantial contributions to the acquisition of the data, interpretation of results and helped to draft and revise the manuscript. AW, DJG and JCMD made substantial contribution to analysis and interpretation of results and helped to draft and revise the manuscript. DJG and JCMD contributed to the development of GenSel software (http://bigs.ansci.iastate.edu/). All authors read and approved the final manuscript.

\section{Acknowledgements}

We are grateful to Bert Dibbits for extracting DNA from all blood samples, to veterinarians drs. Remmen and drs. Dalemans for scoring phenotypes and taking blood samples, to Betteke van Eijk for fast data exchange during busy times and to drs. van Muyden for his enthusiastic help on data collection in Icelandic horses. We thank the Dutch Shetland Pony Studbook (Zutphen) for providing part of the data. Many thanks to all horse owners who contributed to our research. This work was financially supported by technology foundation STW (Utrecht), the Dutch federation of horse breeding Vereniging Koepel Fokkerij (Ermelo), and the (bio)pharmaceutical company Artu Biologicals part of ALK-Abelló (Almere).

\section{Author details}

${ }^{1}$ Animal Breeding and Genomics Centre, Wageningen University, P.O. Box 338, Wageningen $6700 \mathrm{AH}$, the Netherlands. ${ }^{2}$ Department of Genetics and Animal Breeding, Poznan University of Life Sciences, Poznan, Poland. ${ }^{3}$ Department of Animal Science, Center for Integrated Animal Genomics, lowa State University, Ames, USA. ${ }^{4}$ Quantitative Veterinary Epidemiology Group, Wageningen University, P.O. Box 338, Wageningen $6700 \mathrm{AH}$, the Netherlands.

Received: 19 June 2012 Accepted: 19 October 2012

Published: 30 October 2012

\section{References}

1. Gortel K: Equine parasitic hypersensitivity. Equine Pract 1998, 20:14-16.

2. Meiswinkel R, Baylis M, Labuschagne K: Stabling and the protection of horses from Culicoides bolitinos (Diptera: Ceratopogonidae), a recently identified vector of African horse sickness. Bull Ent Res 2000, 90:509-515.

3. de Raat IJ, van den Boom R, van Poppel M, van Oldruitenborgh-Oosterbaan MM S: The effect of a topical insecticide containing permethrin on the number of Culicoides midges caught near horses with and without insect bite hypersensitivity in the Netherlands. Tijdschr Diergeneeskd 2008, 133:838-842.

4. van den Boom R, Kempenaars M, Sloet van Oldruitenborgh-Oosterbaan MM: The healing effects of a topical phytogenic ointment on insect bite hypersensitivity lesions in horses. Tijdschr Diergeneeskd 2011, 136:20-26.

5. Papadopoulos E, Rowlinson M, Bartram D, Carpenter S, Mellor P, Wall R: Treatment of horses with cypermethrin against the biting flies Culicoides nubeculosus, Aedes aegypti and Culex quinquefasciatus. Vet Parasitol 2010, 169:165-171.

6. Eriksson S, Grandinson K, Fikse WF, Lindberg L, Mikko S, Broström H, Frey R, Sundquist M, Lindgren G: Genetic analysis of insect bite hypersensitivity (summer eczema) in Icelandic horses. Animal 2008, 2:360-365.

7. Schurink A, van Grevenhof EM, Ducro BJ, van Arendonk JAM: Heritability and repeatability of insect bite hypersensitivity in Dutch Shetland breeding mares. J Anim Sci 2009, 87:484-490.

8. Schurink A, Ducro BJ, Heuven HCM, van Arendonk JAM: Genetic parameters of insect bite hypersensitivity in Dutch Friesian broodmares. J Anim Sci 2011, 89:1286-1293.

9. Unkel M, Simon D, Mayer M, Sommer H: Studies on the genetic basis of sweet itch in Island horses. Z Tierzücht Züchtungsbiol 1987, 104:217-230.

10. Andersson LS, Swinbune JE, Meadows JRS, Broström H, Eriksson S, Fikse WF, Frey R, Sundquist M, Tseng CT, Mikko S, Lindgren G: The same ELA class II risk factors confer equine insect bite hypersensitivity in two distinct populations. Immunogenetics 2012, 64:201-208. 
11. Halldórsdóttir S, Lazary S, Gunnarsson E, Larsen HJ: Distribution of leucocyte antigens in Icelandic horses affected with summer eczema compared to non-affected horses. Equine Vet J 1991, 23:300-302.

12. Marti E, Gerber H, Lazary S: On the genetic basis of equine allergic diseases: II. Insect bite dermal hypersensitivity. Equine Vet J 1992, 24:113-117.

13. Bailey E, Marti E, Fraser DG, Antczak DF, Lazary S: Immunogenetics of the horse. In The Genetics of the Horse. Edited by Bowling AT, Ruvinsky A. New York: CABI Publishing; 2000:123-155.

14. Schurink A, Ducro BJ, Bastiaansen JWM, Frankena K, van Arendonk JAM: Genome-wide association study of insect bite hypersensitivity in Dutch Shetland pony mares. Anim Genet, . in press.

15. Karlsson EK, Lindblad-Toh K: Leader of the pack: gene mapping in dogs and other model organisms. Nat Rev Genet 2008, 9:713-725.

16. Hayes B, Goddard M: Genome-wide association and genomic selection in animal breeding. Genome 2010, 53:876-883.

17. van den Boom R, Ducro B, van Sloet Oldruitenborgh-Oosterbaan MM: Identification of factors associated with the development of insect bite hypersensitivity in horses in the Netherlands. Tijdschr Diergeneeskd 2008, 133:554-559.

18. Aulchenko YS, Ripke S, Isaacs A, van Duijn CM: GenABEL: an R library for genome-wide association analysis. Bioinformatics 2007, 23:1294-1296.

19. Gower JC: Some distance properties of latent root and vector methods used in multivariate analysis. Biometrika 1966, 53:325-338.

20. Kizilkaya K, Fernando RL, Garrick DJ: Genomic prediction of simulated multibreed and purebred performance using observed fifty thousand single nucleotide polymorphism genotypes. J Anim Sci 2010, 88:544-551.

21. Fernando RL, Garrick DJ: GenSel - User manual for a portfolio of genomic selection related analyses. Ames: Animal Breeding and Genetics, lowa State University; 2008. http://bigs.ansci.iastate.edu/bigsgui/login.html

22. Fan B, Onteru SK, Du ZQ, Garrick DJ, Stalder KJ, Rothschild MF: Genomewide association study identifies loci for body composition and structural soundness traits in pigs. PLOS ONE 2011, 6:e14726.

23. Onteru SK, Fan B, Du Z-Q, Garrick DJ, Stalder KJ, Rothschild MF: A wholegenome association study for pig reproductive traits. Anim Genet 2011, 43:18-26.

24. Meuwissen THE, Hayes BJ, Goddard ME: Prediction of total genetic value using genome-wide dense marker maps. Genetics 2001, 157:1819-1829.

25. Sorensen DA, Andersen S, Gianola D, Korsgaard I: Bayesian inference in threshold models using Gibbs sampling. Genet Sel Evol 1995, 27:229-249.

26. Gianola D, de los Campos G, Hill WG, Manfredi E, Fernando R: Additive genetic variability and the Bayesian alphabet. Genetics 2009, 183:347-363.

27. Sun X, Habier D, Fernando RL, Garrick DJ, Dekkers JCM: Genomic breeding value prediction and QTL mapping of QTLMAS2010 data using Bayesian methods. BMC Proc 2011, 5:S13.

28. Wolc A, Arango J, Settar P, Fulton JE, O'Sullivan NP, Preisinger R, Habier D, Fernando R, Garrick DJ, Hill WG, Dekkers JCM: Genome-wide association analysis and genetic architecture of egg weight and egg uniformity in layer chickens. Anim Genet 2012, 43:87-96.

29. Pilsworth RC, Knottenbelt DC: Equine insect hypersensitivity. Equine Vet Educ 2004, 16:324-325.

30. Hirschhorn JN, Daly MJ: Genome-wide association studies for common diseases and complex traits. Nat Rev Genet 2005, 6:95-108.

31. Toosi A, Fernando RL, Dekkers JCM: Genomic selection in admixed and crossbred populations. J Anim Sci 2010, 88:32-46.

32. Broström H, Larsson $\AA$, Troedsson M: Allergic dermatitis (sweet itch) of Icelandic horses in Sweden: an epidemiological study. Equine Vet J 1987 19:229-236

33. Marti E, Gerber V, Wilson AD, Lavoie JP, Horohov D, Crameri R, Lunn DP, Antczak D, Björnsdóttir S, Björnsdóttir TS, Cunningham F, Dérer M, Frey $R$ Hamza E, Horin P, Heimann M, Kolm-Stark G, Ólafsdóttir G, Ramery E, Russell C, Schaffartzik A, Svansson V, Torsteinsdóttir S, Wagner B: Report of the 3rd Havemeyer workshop on allergic diseases of the Horse, Hólar, Iceland, June 2007. Vet Immunol Immunopathol 2008, 126:351-361.

34. Björnsdóttir S, Sigvaldadóttir J, Broström H, Langvad B, Sigurðsson Á: Summer eczema in exported Icelandic horses: influence of environmental and genetic factors. Acta Vet Scand 2006, 48:3.

35. Mucha S, Pszczoła M, Strabel T, Wolc A, Paczyńska P, Szydlowski M: Comparison of analyses of the QTLMAS XIV common dataset. II: QTL analysis. BMC Proc 2011, 5:S2
36. Sahana G, Guldbrandtsen B, Janss L, Lund MS: Comparison of association mapping methods in a complex pedigreed population. Genet Epidemiol 2010, 34:455-462.

37. He W, Fernando RL, Dekkers JCM, Gilbert H: A gene frequency model for QTL mapping using Bayesian inference. Genet Sel Evol 2010, 42:21.

38. Smith AV, Thomas DJ, Munro HM, Abecasis GR: Sequence features in regions of weak and strong linkage disequilibrium. Genome Res 2005, 15:1519-1534.

39. Bohmanova J, Sargolzaei M, Schenkel FS: Characteristics of linkage disequilibrium in North American Holsteins. BMC Genomics 2010, 11:421.

40. Dekkers JCM, Hospital F: The use of molecular genetics in the improvement of agricultural populations. Nat Rev Genet 2002, 3:22-32.

41. de Roos APW, Hayes BJ, Spelman RJ, Goddard ME: Linkage disequilibrium and persistence of phase in Holstein-Friesian, Jersey and Angus cattle. Genetics 2008, 179:1503-1512.

42. van de Goor LHP, van Haeringen WA, Lenstra JA: Population studies of 17 equine STR for forensic and phylogenetic analysis. Anim Genet 2011, 42:627-633.

43. Hill WG, Robertson A: Linkage disequilibrium in finite populations. Theor Appl Genet 1968, 38:226-231.

44. Wade CM, Giulotto E, Sigurdsson S, Zoli M, Gnerre S, Imsland F, Lear TL, Adelson DL, Bailey E, Bellone RR, Blöcker H, Distl O, Edgar RC, Garber M, Leeb T, Mauceli E, MacLeod JN, Penedo MCT, Raison JM, Sharpe T, Vogel J, Andersson L, Antczak DF, Biagi T, Binns MM, Chowdhary BP, Coleman SJ, Della Valle G, Fryc S, Guérin G, et al: Genome sequence, comparative analysis, and population genetics of the domestic horse. Science 2009, 326:865-867.

45. Andersson LS, Högström C, Mikko S, Eriksson S, Grandinson K, Broström H, Frey R, Sundquist M, Lindgren G: Polymorphisms in SPINK5 do not associate with insect bite hypersensitivity in Icelandic horses born in Sweden. Anim Genet 2009, 40:790-791.

46. Hořín P, Smola J, Matiašovic J, Vyskočil M, Lukeszová L, Tomanová K, Králík P, Glasnák V, Schröffelová D, Knoll A, Sedlinská M, Křenková L, Jahn P: Polymorphisms in equine immune response genes and their associations with infections. Mamm Genome 2004, 15:843-850.

47. Marti E, Glowatzki-Mullis ML, Curik I, Torsteinsdottir S, Binns MM: Investigating the genetic background for insect bite hypersensitivity in Icelandic horses. In Proceedings of the 6th International Equine Gene Mapping Workshop. Edited by. Dublin; 2005.

48. Chowdhary BP, Raudsepp T: The horse genome derby: racing from map to whole genome sequence. Chromosome Res 2008, 16:109-127.

49. Dekkers JCM: Commercial application of marker- and gene-assisted selection in livestock: strategies and lessons. J Anim Sci 2004, 82:E313-E328.

doi:10.1186/1297-9686-44-31

Cite this article as: Schurink et al:: Genome-wide association study of insect bite hypersensitivity in two horse populations in the Netherlands. Genetics Selection Evolution 2012 44:31.

\section{Submit your next manuscript to BioMed Central and take full advantage of:}

- Convenient online submission

- Thorough peer review

- No space constraints or color figure charges

- Immediate publication on acceptance

- Inclusion in PubMed, CAS, Scopus and Google Scholar

- Research which is freely available for redistribution 